\title{
Price Behaviour and Constraints in the Small Cardamom
}

\author{
R. Vishnu ${ }^{1 *}$, C. Velavan ${ }^{2}$, S. D. Sivakumar ${ }^{3}$ and G. V. Rajalingam ${ }^{4}$ \\ ${ }^{1}$ Department of Agricultural and Rural Management, ${ }^{2}$ Directorate of Planning and \\ Monitoring, ${ }^{3}$ Agribusiness Development, ${ }^{4}$ Department of Vegetable Crops, \\ Tamil Nadu Agricultural University, Coimbatore, Tamil Nadu - 641003 \\ *Corresponding author
}

\section{Keywords}

Small cardamom,

Price behaviour,

Constraints, Trend,

Seasonal, Cyclical,

Irregular

Article Info

Accepted:

15 November 2019

Available Online:

10 December 2019
Small cardamom is a perennial crop which is cultivated predominantly along the Western Ghats of South India. Small cardamom is one of the costly spices after saffron and vanilla. Though the cardamom is a highvalue export-oriented spice crop, there were high price fluctuations over the period. Hence, an attempt was made to study the price behaviour of small cardamom along with that constraints faced by farmers also studied.

\section{Introduction}

Cardamom is a tropical perennial herb belongs to the ginger family (Zingiberaceae), mostly cultivated in the Western Ghats of South India. Guatemala is the world's largest producer of cardamom followed by India. However, Indian cardamom is highly preferred spices in the international market for its' superior aroma and taste. India exported 3,850 tonnes of small cardamom to the value of Rs. 421.50 crores during the year 20162017. Saudi Arabia is the major small cardamom importer from India, which imported 2,500 tonnes to the value of Rs.275 crores during 2016-2017 (Spices Board, 2018). The other major importing countries are UAE, Kuwait, USA and Japan, Malaysia, Israel, UK, Canada, Pakistan, Australia, and South Africa.

There is a wide gap between the average and high price of small cardamom. Farmers are highly affected due to these price fluctuations. As an exceptional commodity, cardamom experience peak price in the peak season due 
to its deterioration of green colour in storage and have high intra-year price instability (Anoopkumar, 2012). The fluctuation in production leads to uncertainty in the product supply for exports which in turn leads to the volatility of export prices. In this condition, the present study was conducted to study the price behaviour of small cardamom and constraints faced by the farmers.

\section{Materials and Methods}

\section{Sampling}

Idukki district of Kerala and Theni district of Tamil Nadu were purposively selected for the study based on the largest area under cardamom in the respective state. From each selected district, one taluk was selected based on the largest area under cardamom. From each selected taluk three villages were selected by random and 20 farmers selected from each village by random sampling. Thus, the total sample accounted for 120 farmers with 60 farmers from each state. These sample respondents were used to identify the constraints faced by the farmers. Secondary data on the prices of cardamom were collected from the website and publication of the spice board (www.indianspices.com) for the study of price behaviour.

\section{Price analysis}

Time series analysis was used to study the periodical fluctuations in the price of the cardamom. Time series is a mixture of four components namely trend, seasonal variation, cyclical variation and irregular variation. The relationships among these components are assumed to be additive or multiplicative. The multiplicative method was used in this study, the following formula was used in this study;

$\mathrm{P}_{\mathrm{t}}=\mathrm{T}_{\mathrm{t}} \times \mathrm{S}_{\mathrm{t}} \times \mathrm{C}_{\mathrm{t}} \times \mathrm{I}_{\mathrm{t}}$
Where,

$$
\begin{aligned}
& \mathrm{P}_{\mathrm{t}}=\text { Price in time } \\
& \mathrm{T}_{\mathrm{t}}=\text { Trend component } \\
& \mathrm{S}_{\mathrm{t}}=\text { Seasonal variations } \\
& \mathrm{C}_{\mathrm{t}}=\text { Cyclical variations } \\
& \mathrm{I}_{\mathrm{t}}=\text { Irregular variations }
\end{aligned}
$$

\section{Trend component}

Prices have a tendency to increase and decrease over a long period of time. There are different types of trend, linear trend for shorter period and non-linear trend for the longer period would be observed. For estimating trend of prices, the method of least squares estimate was employed to ascertain trend in prices by estimating the coefficients $a$ and $b$ in following linear functional form:

$P_{t}=a+b T_{t}$

Where,

$\mathrm{P}_{\mathrm{t}}=$ Price during the month $\mathrm{t}$

$T_{t}=$ Serial number assigned to the $t^{\text {th }}$ month

$\mathrm{a}=$ Intercept

$\mathrm{b}=$ Regression coefficient

\section{Seasonal variations}

The seasonal variation is within an account of customs, climates, etc. such seasonal components can be analyzed through harmonic analysis. The time series which usually show variation in regular pattern in a period of one year. The component of the time series that represent the variability in the data due to seasonal fluctuation is called seasonal variation.

To estimate the seasonal index, a 12-month centred moving average was calculated to remove large part of fluctuation (trend and cyclical components) and irregular component was minimized by smoothing out effect. The percentages of moving averages were 
arranged in form of monthly patterns and average index of each month was calculated and adjusted such that their sum became 1200 .

\section{Cyclical variations}

Cyclical movements are fluctuations which differ from period to period. It is mainly due to differences in demand and supply of the commodities. The cyclical movement has a longer duration than a year for different lengths with different phases of price movements similar to business cycle. The cyclical movements were worked out by dividing the moving average with estimated trend values.

$C=\frac{T \cdot C}{T}$

\section{Irregular variations}

The irregular variation of time series is the residual factor that accounts for deviations of actual time series value from those expected given the effects of trend, cyclical and seasonal variation. It is caused by the short term; nonrecurring and unanticipated factors that affect time series like flood, earthquake and many more. The irregular component in the price was worked out by dividing the price with above three components.

$I=\frac{P}{T \cdot C \cdot S}$

\section{Garrett ranking technique}

Garrett Ranking Technique was used to identify major constraints in production and marketing of small cardamom. The growers were asked to rank the identified constraints in production and marketing. The orders of merit assigned by the respondents were converted into scores by using the Garret table. The following formula was used to convert the scores into percent position.

Percent position $=\underline{100 \times(\mathrm{Rij}-0.5)}$

$\mathrm{Nj}$

Where,

Rij $=$ Ranking given for the $\mathrm{i}^{\text {th }}$ variable by the

$\mathrm{j}^{\text {th }}$ respondents

$\mathrm{Nj}=$ Number of variables ranked by $\mathrm{j}^{\text {th }}$ respondent.

For each factor, scores of each respondent were added and then the total value of scores and mean values of score was calculated. The factors having highest mean value was considered to be the most important factor.

\section{Results and Discussion}

\section{Price behaviour of small cardamom}

Price behaviour aids farmer to plan for future activities. Farm budgeting is largely dependent upon expected future price. Therefore, studying price behaviour is of utmost importance. As discussed earlier in the design of study chapter, the price behaviour of small cardamom was studied. The small cardamom price increased during the harvest period as an exceptional commodity due to its colour and pungency which could reduce over the period of time (Anoopkumar, 2012).

From Figure 1, it was visible that the price of the small cardamom highly fluctuated from 2008 - 2018. The lowest price was during December of 2008 (Rs. 440.22) and the highest price was during June of 2010 (Rs. 1516.66).

\section{Trend analysis}

The study on trend enables us to indicate the general direction of price. The analysis revealed that there was an increasing trend of prices over the study period with a monthly increase of Rs. 2.43 per kilogram (Table 1). 
There was a gradual increase in the price till June 2010 (Rs. 1516.66) after that price had decreased and the price reached its peak during January 2017. There was an increase in price during June 2010 due to low supply of small cardamom 15-20 tonnes when compared to normal supply of 50 tonnes of small cardamom during this season (Krishnakumar, 2010). The trend of the small cardamom prices is presented in Figure 1.

Table.1 Linear trend equation for monthly auction price of small cardamom (2008-2018)

\begin{tabular}{|c|l|l|l|l|l|}
\hline S.No & Particulars & Coefficient & Standard error & t Stat & P - value \\
\hline 1. & Intercept & 645.03 & 40.18 & 16.05 & $1.218 \mathrm{E}^{-32}$ \\
\hline 2. & Time period & 2.43 & 0.52 & 4.63 & $8.753 \mathrm{E}^{-06}$ \\
\hline
\end{tabular}

Table.2 Major constraints in small cardamom production

\begin{tabular}{|c|l|c|c|}
\hline S. No & \multicolumn{1}{|c|}{ Constraints } & Score & Rank \\
\hline $\mathbf{1 .}$ & Labour shortage & 61.20 & I \\
\hline $\mathbf{2 .}$ & High variation in rainfall & 58.53 & II \\
\hline $\mathbf{3 .}$ & High input cost & 52.90 & III \\
\hline $\mathbf{4 .}$ & High cost of production & 51.92 & IV \\
\hline $\mathbf{5 .}$ & High wage rate & 51.48 & V \\
\hline $\mathbf{6 .}$ & Lack of credit support & 45.77 & VI \\
\hline 7. & High pest and disease incidence & 27.73 & VII \\
\hline
\end{tabular}

Table.3 Major constraints in small cardamom marketing

\begin{tabular}{|c|l|c|c|}
\hline S.no & \multicolumn{1}{|c|}{ Constraints } & Score & Rank \\
\hline $\mathbf{1 .}$ & High price fluctuation & 66.88 & I \\
\hline $\mathbf{2 .}$ & Absence of grading & 64.77 & II \\
\hline $\mathbf{3 .}$ & Inadequate quantity to market & 51.03 & III \\
\hline $\mathbf{4 .}$ & Absence of curing facility & 50.90 & IV \\
\hline $\mathbf{5 .}$ & High commission charges & 41.77 & V \\
\hline $\mathbf{6 .}$ & High cost of transportation & 41.57 & VI \\
\hline $\mathbf{7 .}$ & Lack of storage facility & 32.32 & VII \\
\hline
\end{tabular}


Figure.1 Trend line and monthly auction prices of small cardamom

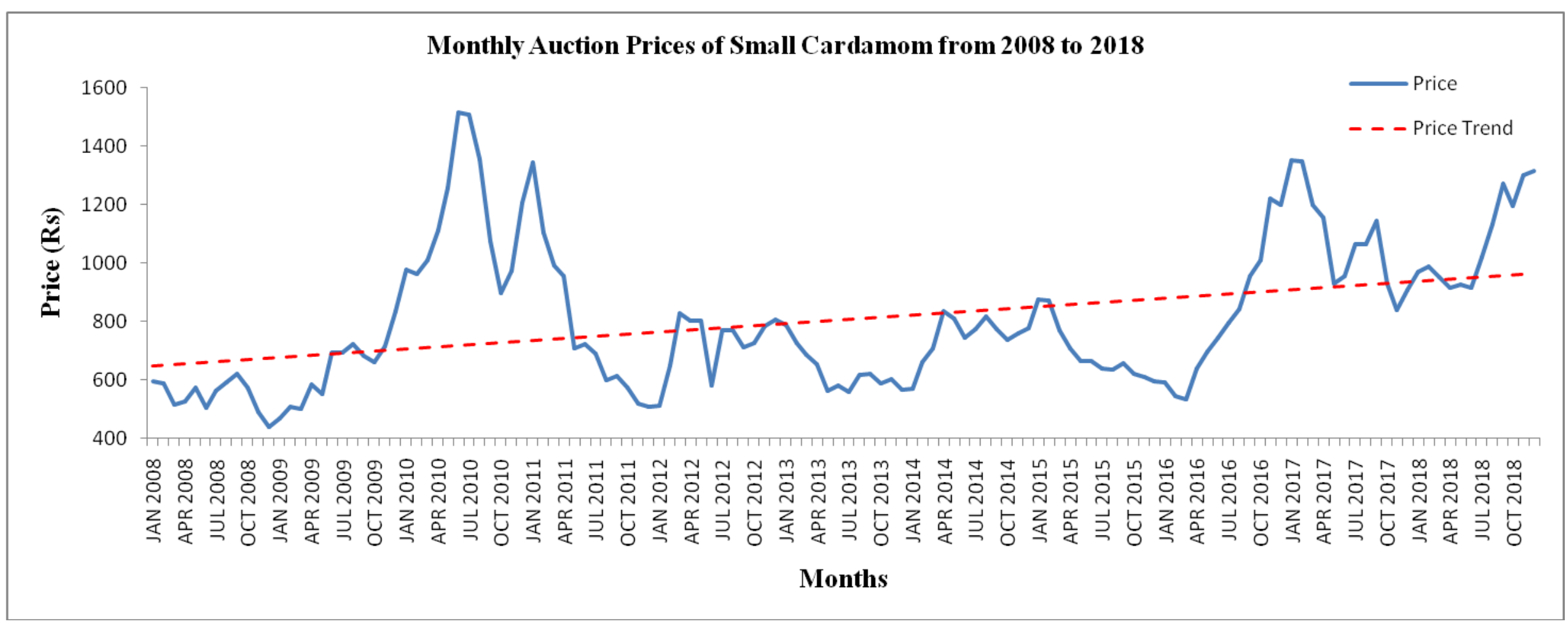


Int.J.Curr.Microbiol.App.Sci (2019) 8(12): 1901-1909

Figure.2 Seasonal variations of small cardamom price

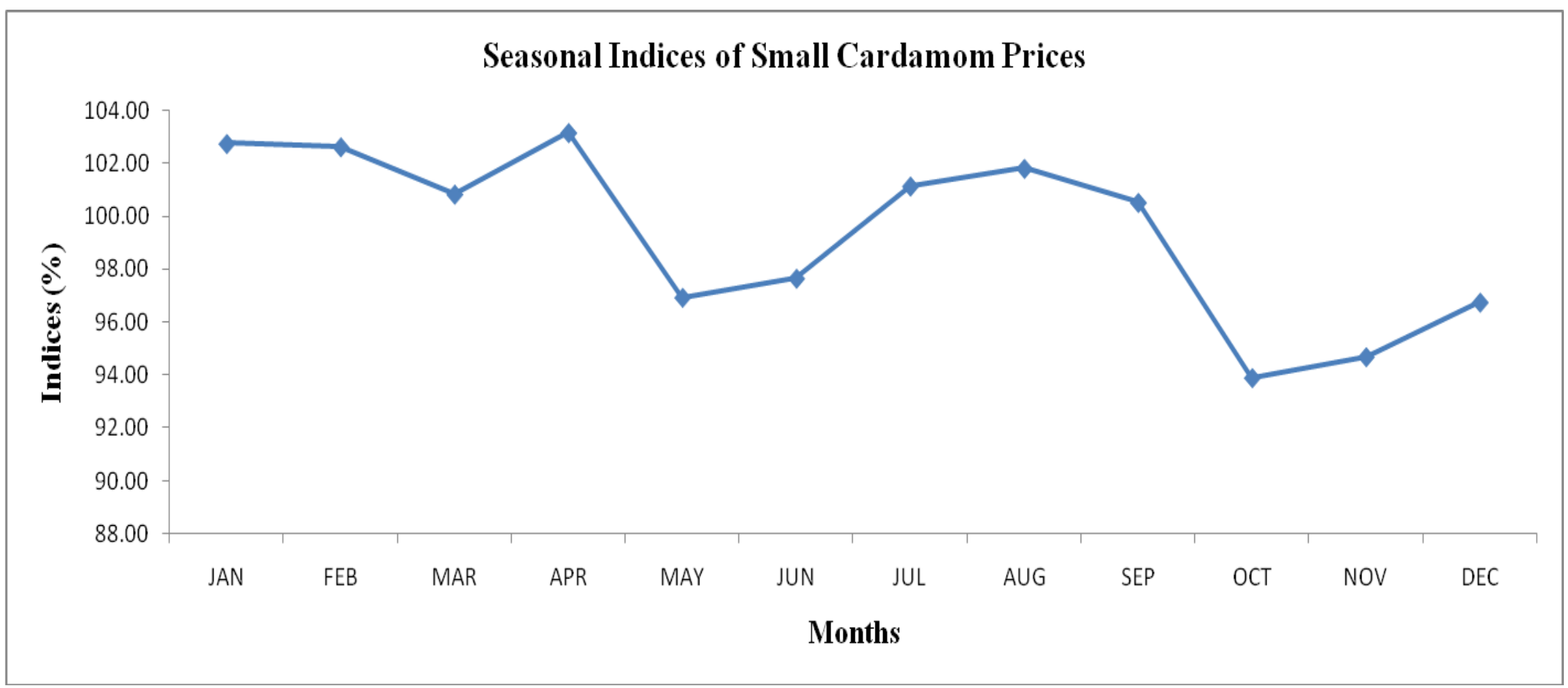




\section{Int.J.Curr.Microbiol.App.Sci (2019) 8(12): 1901-1909}

Figure.3 Cyclical and irregular variations of small cardamom prices

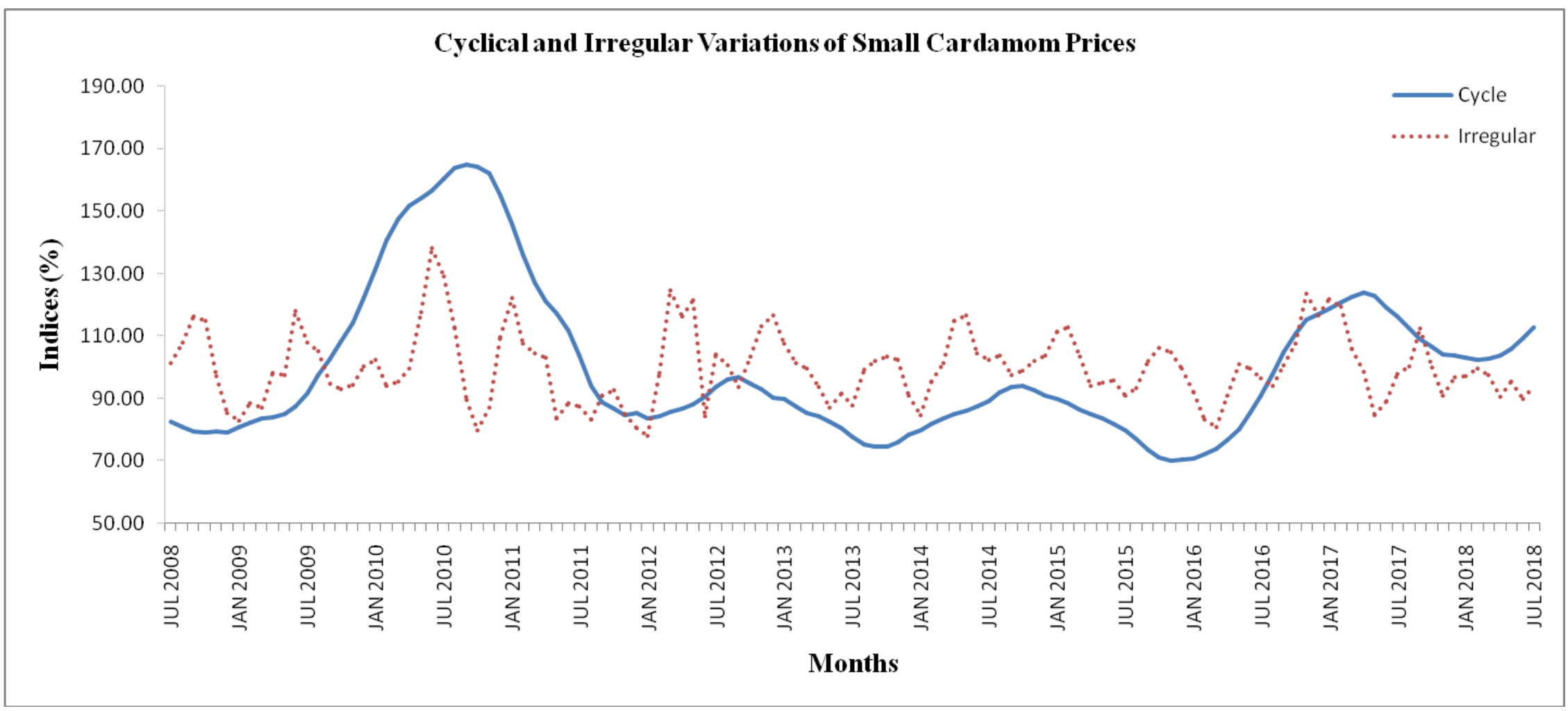




\section{Seasonal variations}

The seasonal indices of monthly auction prices of small cardamom are presented in Figure 2. The seasonal index was maximum during April (103.15) and minimum during October (93.91). There was a decline of index during the harvest period (October) and steady upward movement was observed till next harvest (April). The price index was low during the off-season (May and June) after that gradual increase till August was observed.

\section{Cyclical movements}

Price cycle represents deviations in price levels from the average trend. Cyclical movements are of a longer duration usually extending to a few years. Figure 3 presents the cyclical variations of small cardamom prices. There was a cycle observed in the initial years after that it was diminished over the years.

\section{Irregular variations}

Irregular price movements represent that part of the price behaviour, which does not exhibit any systematic pattern. The random variations are minor fluctuations not attributable to specific events and are too small to merit individual consideration. Figure 3 presents the irregular variations of the small cardamom prices which revealed that prices were subjected to high irregular variations during the period of the study. They represented random effects such as demand and supply shocks.

\section{Constraints faced by the small cardamom} farmers

The constraints faced by the producers in cardamom production and marketing in Theni and Idukki district sample farmers were ranked using Garret ranking technique. The results of the analysis are presented in Table 2 and Table 3.
It could be inferred from the Table 2 that majority of the sample farmers ranked labour shortage was the major constraint in production followed by high variation in rainfall and high input cost ranked as second and third constraint respectively. The high cost of production and high wage rate were ranked fourth and fifth constraint respectively. Lack of credit support and high pest and disease incidence were ranked sixth and seventh constraint respectively. Hence, the steps have to be taken to improve labour availability and reduce the risks of variation in rainfall. Introduction of machinery for various field operations may reduce the dependence of labour. Further, rainwater may be harvested at the farm level and water may be used during the period of shortages.

It could be inferred from the Table 3 that majority of the sample farmers ranked high price fluctuation was the major constraints in cardamom marketing followed by the absence of grading and inadequate quantity to market as second and third constraints respectively. Absence of curing facility and high commission charges were fourth and fifth constraint respectively. The high cost of transportation and lack of storage facility were ranked sixth and seventh constraint respectively. Hence, forecasting of cardamom price and dissemination by the Spices Board could reduce the price risk to the farmers. Further, popularization trading standards and promotion of grading practices among farmers and village traders could also help for better price realization by all the stakeholders.

In conclusion, the price of the small cardamom highly fluctuated from 2008 2018. The lowest price was during December of 2008 (Rs. 440.22) and the highest price was during June of 2010 (Rs. 1516.66). There was a rising trend in prices with a monthly increase of Rs. 2.43 per kilogram. The seasonal index was maximum during April (103.15) and 
minimum during October (93.91). There was a cycle observed in the initial years after that it was diminished over the years. Irregular price movements did not exhibit any systematic pattern. Irregular variations of the small cardamom price which revealed that prices were subjected to high irregular movements during the period of the study. They represented random effects such as demand and supply shocks. Forecasting the cardamom price by the Spices Board and dissemination the same among the stakeholder would be helpful to reduce the price risk.

It could be found that labour shortage was the major constraint which ranks first in production followed by high variation in rainfall and high input cost. Majority of the sample farmers ranked high price fluctuation was the major constraints in cardamom marketing followed by the absence of grading and inadequate quantity to market. Hence, the introduction of appropriate machinery in production and post-harvest operations may reduce the dependence of human labour. The creation of rainwater harvesting structures in the farm would be helpful to reduce the water scarcity and improve the yield of the crop. Popularization of the trading standards and promotion of grading practices among farmers and traders would be helpful to get a better price for cardamom.

\section{References}

Spices Board, Annual Report 2017-2018, Government of India, 2018.

Anoopkumar, M. 2014. "Intra-Year Price Instability of Commercial Crops In India: Exploring the Underlying Dynamism." International Journal of Food and Agricultural Economics (IJFAEC) 2 (1):145-156.

Krishnakumar, P K. 2010. "Cardamom: Low Output to keep Prices at a High till Harvest." ET Bureau, June 14.

\section{How to cite this article:}

Abhijeet Satpathy, Subrat Kumar Mahapatra and Rituparna Mohapatra. 2019. Price Behaviour and Constraints in the Small Cardamom. Int.J.Curr.Microbiol.App.Sci. 8(12): 1901-1909. doi: https://doi.org/10.20546/ijcmas.2019.812.227 